\title{
The Association Between Strength, Balance and Physical Function with the Body Mass Index in Dyslipidemia
}

\author{
Ercan $\mathrm{S}^{*}$, Demir $\mathrm{HM}^{2}$ and Cetin $\mathrm{C}^{3}$ \\ ${ }^{1}$ Department of Sports Medicine, Dr. Ersin Arslan Education and Research Hospital, Gaziantep, Turkey \\ ${ }^{2}$ Department of Sports Medicine, Van Education and Research Hospital, Van, Turkey \\ ${ }^{3}$ Department of Sports Medicine, Faculty of Medicine, Suleyman Demirel University, Isparta, Turkey
}

*Corresponding author: Ercan S, Department of Sports Medicine, Dr. Ersin Arslan Education and Research Hospital, Gaziantep, Turkey, Tel: +903423241111, E-mail: sabriyeercan@gmail.com

Citation: Ercan S, Demir HM, Cetin C (2018) The Association Between Strength, Balance And Physical Function With The Body Mass Index In Dyslipidemia. J Obes Overweig 4(1): 102. doi: 10.15744/2455-7633.4.102

Received Date: December 05, 2017 Accepted Date: May 24, 2018 Published Date: May 26, 2018

\begin{abstract}
Introduction: The coexistence of chronic diseases has led to greater negativity in patients than the negativity of diseases individually speaking. The aim of this study was to investigate the effects of the body mass index on metabolic profile, isometric and isokinetic muscle strength, static and dynamic balance, and anaerobic capacity in dyslipidemia patients, as well as to emphasize what exercises should be recommended for recovering the experienced functional loss of the patients.

Materials and Methods: Forty five patients (26 women, 19 men) between 40 and 75 years of age and who were newly diagnosed as dyslipidemia were enrolled into this study. The patients were divided into two groups according to their body mass indexes (BMI): group 1 (n:18) or those whose BMI was lower than $25 \mathrm{~kg} / \mathrm{m}^{2}$, and group 2 (n:27) or those whose BMI was higher than $30 \mathrm{~kg} / \mathrm{m}^{2}$. Biochemical blood sampling was done. The Get Up and Go, single leg stance, anaerobic capacity, and isometric as well as isokinetic muscle strength tests were performed in order to evaluate functional capacities.

Results: There were no statistically significant differences shown at gender distribution, age, or height ( $>0.05)$ between groups. The weight and BMI's between the groups were statistically significantly different $(\mathrm{p}<0.05)$. The fasting glucose levels and triglyceride levels of group 2 was statistically significantly higher than group $1(\mathrm{p}<0.05)$, whereas other biochemical parameters showed no differences $(\mathrm{p}>0.05)$. The static balance tests results between groups have shown no statistically significant differences $(\mathrm{p}<0.05)$; however the dynamic balance test results for group 2 was statistically significantly worse than those of group $1(p<0.05)$. The parameters of the results of the anaerobic testing, alongside those of the isometric and isokinetic testing for group 1 patients were statistically significantly higher than those of group $2(\mathrm{p}<0.05)$.

Conclusion: Obesity negatively affects dyslipidemic patients' metabolic and functional capacities. An exercise program for dyslipidemic patients with a high BMI should include strengthening and balance as well as dynamic balance exercises in order to positively influence both their metabolic profiles and functional status.
\end{abstract}

Keywords: Hyperlipidemia; Obesity; Physical fitness

\section{Introduction}

Dyslipidemia referrers to hypertiglyceridemia, low serum high-density lipoprotein (HDL) cholesterol levels, and high serum lowdensity lipoprotein (LDL) cholesterol levels. The prevalence of dyslipidemia is widespread. This prevalence is increasing day by day due to a Western-style diet, obesity, and a lack of physical activity [1]. Obesity is fat accumulation within the body due to an imbalance between energy intake and expenditure. Obesity detection can be done according to the fat ratio or according to the body mass index (BMI) based upon the criteria of the World Health Organization. According to the BMI classification system, a BMI equaling or over than $30.00 \mathrm{~kg} / \mathrm{m}^{2}$ is classified as obese, and BMI between 18.50 to $24.99 \mathrm{~kg} / \mathrm{m}^{2}$ is classed as normal [2]. Obesity predisposes one to chronic diseases such as hypertension, type 2 diabetes mellitus, osteoarthritis and certain types of cancer [3]. Moreover, obesity and the diseases that accompany it will increase the risk of mortality and morbidity [4].

Recent studies done in Turkey indicate that within the Turkish population there is a high total cholesterol level of $43 \%$, a low HDL of $41.5 \%$, a high LDL of $36.2 \%$, a hypertriglyceridemia level of $35.7 \%$, a $44.2 \%$ obesity rate among females, and a $25.2 \%$ obesity rate among males, and that these results positively correlate to age, BMI, waist circumferences, fasting plasma glucose levels, and blood pressure [1,5]. Lowering the dyslipidemia and obesity will lower the cardiovascular mortality and morbidity [1]. 
Insulin resistance, chronic inflammation, lipotoxicity, muscular dysfunction (the lowering of the muscular activation, strength, and quality), and mobility dysfunction (the lowering of the walking speed and physical performance) occurs due to physical inactivity, obesity, and higher age [6]. Several studies have shown that aerobic and anaerobic capacity, postural balance, functional performances, muscle strength, and endurances lower with obesity [3,7-12]. The coexistence of chronic diseases has led to greater negativity in patients than the negativity of diseases individually speaking [13]. It is foreseen that the metabolic and functional performances of dislipidemic obese patients will be significantly affected. In the literature, studies that have examined the functional losses of dyslipidemic patients according to their body mass indexes were insufficient. In this study, we had first had aimed to examine the effect of the body mass index on the metabolic profile, isometric-isokinetic muscle strength, static-dynamic balance, anaerobic capacity in dyslipidemia patients. We secondly have tried to emphasize what exercises should be recommended for recovering the function loss that patients experience.

\section{Materials and Methods}

Forty five patients (26 women, 19 men) between 40 and 75 years of age and who were newly diagnosed with dyslipidemia according to biochemical analysis were enrolled into this study. Patients who had been using dyslipidemic drugs those with hypothyroidism-due to their effects on lipid metabolism and obesity--as well as those with a BMI between 25 to $29.9 \mathrm{~kg} / \mathrm{m}^{2}$ were not enrolled into this study [14].

The criteria of the National Cholesterol Education Program ATP III were used to diagnose dyslipidemia. A total cholesterol level that is higher than $200 \mathrm{mg} / \mathrm{dL}$ is known as total cholesterolemia, serum triglycerides (TG) levels that higher than $150 \mathrm{mg} / \mathrm{dL}$ is referred to as hypertriglyceridemia, serum HDL cholesterol levels that are lower than $50 \mathrm{mg} / \mathrm{dL}$ for male patients and lower than $40 \mathrm{mg} / \mathrm{dL}$ for female patients is known as low HDL cholesterolemia, and serum LDL cholesterol levels that are higher than 130 $\mathrm{mg} / \mathrm{dL}$ is referred to as high LDL cholesterolemia [1].

Biochemical sampling (for fasting blood glucose, insulin, HOMA IR, triglyceride, total cholesterol, HDL, LDL, Thyroid-Stimulating Hormone (TSH)) were done after 12 hours of fasting [15]. The HOMA (homeostais model assessment) value, which reflects insulin resistance, is calculated as the 'serum fasting glucose level $(\mathrm{mg} / \mathrm{dL}) \mathrm{x}$ fasting plasma insulin level $(\mu \mathrm{U} / \mathrm{mL}) / 405$ ' formula. Insulin resistance is accepted should the HOMA-IR results be above $\geq 2.5$ [16].

Body weights measured with a balance beam scale and heights were measured using a stadiometer (SECA 700, Germany). The body mass index is measured by dividing the body mass by the square of the body height [1].Patients were divided into 2 groups according to BMI. Group 1 includes patients with a BMI of lower than ' $25 \mathrm{~kg} / \mathrm{m}^{2}$ ', and group 2 includes those with a BMI of higher than ' $30 \mathrm{~kg} / \mathrm{m}^{2}$ ' [17].

Tests were commenced after measuring the arterial tension on the condition that there were no contraindications. The Get Up and Go test (15 meters) was performed in order to evaluate the performance-related dynamic balances of the patients, and the Single leg Stance test (30 seconds) was performed in order to evaluate their the static balances [18,19]. The time to finish test was recorded for the Get Up and Go Test, and the number of errors within 30 seconds was recorded for the single leg stance test [20].

A 10-minute submaximal cycle ergometer was done before, as well as 5 minute stretching exercises were done both before and after the strength and anaerobic capacity tests. The Wingate anaerobic capacity test Wingate Test System $894 \mathrm{E}$ was used for $5 \%$ of body weight for 20 seconds [8,21]. An isokinetic dynamometer (HUMAC ${ }^{\oplus}$ NORM $^{\mathrm{TM}}$ Testing \& Rehabilitation System, USA) was used for muscle strength testing. Trial tests had been performed before the tests. As the knee mainly uses concentric contractions during daily activities, the concentric mode was used for the isokinetic tests [22]. The isometric muscle strength test was performed at a $45^{\circ}$ knee extension at a maximal effort of 5 [23]; the isokinetic muscle strength test was applied to the dominant leg at $60^{\circ} / \mathrm{second}$ (5 repetition) and $240 \%$ second (15 repetition) angular velocities at a $0^{\circ}$ extension and $90^{\circ}$ flexion range of joint motion [24,25].

The approval by the ethics committee of this study, which conforms to the Declaration of Helsinki, was obtained during a meeting with local ethics committee.

All of data was analyzed via the SPSS 22.0 package program. Descriptive statics were used in order to identify the data. The Skewness-Kurtosis test had verified that some of the parameters were non-homogenous. Thus Mann-Whitney U tests were done in order to evaluate whether or not any differences had existed between the groups. $\mathrm{p}<0.05$ was considered to be statistically significant. The results were given as median \pm standard error.

\section{Results}

Eighteen of the patients' BMI levels were within normal limits (18.5-24.9 kg/m²), whilst and twenty-seven of the patients' BMI level fell within the category of obese $\left(>30 \mathrm{~kg} / \mathrm{m}^{2}\right)$. The age, height, body weight and BMI values of group 1 (12 female, 6 male) patients were $55.9 \pm 12$ years, $164 \pm 11.7 \mathrm{~cm}, 57.2 \pm 9.9 \mathrm{~kg}$ and $21.3 \pm 2.9 \mathrm{~kg} / \mathrm{m}^{2}$. For group 2 (14 females, $13 \mathrm{males}$ ), these values were $56.7 \pm 10.5$ years, $156.6 \pm 7.4 \mathrm{~cm}, 83 \pm 9.8 \mathrm{~kg}$ and $33.8 \pm 3.4 \mathrm{~kg} / \mathrm{m}^{2}$, respectively. There were no differences found between groups' in terms of the gender distribution $(\mathrm{p}=0.5)$, height $(\mathrm{p}=0.2)$ or age $(\mathrm{p}=0.9)$ of the patients. However statistically significant differences were found between groups when it came to body weight and BMI values $(\mathrm{p}=0.001)$. 
All patients in this study have both high total cholesterolemia as well as high LDL cholesteremia. Additionally, 3 of the patients from group 1 and 16 of the patients from group 2 have hypertriglyceridemia; 4 patients from group 1 and 12 patients from group 2 have low HDL cholesterolemia, and 3 patients from group 1 as well as 18 patients from group 2 have insulin resistance. The biochemical results of the patients were shown in Table 1. The fasting blood glucose levels and triglyceride levels were statistically significantly higher among group 2 patients $(\mathrm{p}<0.05)$; however, no differences were found between any of the other biochemical parameters between the two groups $(\mathrm{p}>0.05)$.

\begin{tabular}{|c|c|c|c|}
\hline & Group 1 (n:18) & Group 2 (n:27) & p value \\
\hline Glucose $(\mathbf{m g} / \mathbf{d L})$ & $93.5 \pm 7.5$ & $124.3 \pm 31.6$ & $\mathbf{0 . 0 0 1}^{*}$ \\
\hline Insulin $(\boldsymbol{\mu U} / \mathbf{m L})$ & $18.6 \pm 31.6$ & $22.7 \pm 20.4$ & 0.2 \\
\hline HOMA IR & $4.2 \pm 6.9$ & $7.9 \pm 8.4$ & 0.1 \\
\hline Triglyceride & $123.3 \pm 41.4$ & $161.3 \pm 50.2$ & $\mathbf{0 . 0 4}^{*}$ \\
\hline $\begin{array}{c}\text { Total cholesterol } \\
(\mathbf{m g} / \mathbf{d L})\end{array}$ & $274.6 \pm 61.7$ & $259 \pm 33$ & 0.8 \\
\hline HDL (mg/dL) & $59.6 \pm 16.9$ & $48.1 \pm 8.6$ & 0.08 \\
\hline LDL $(\mathbf{m g} / \mathbf{d L})$ & $190.6 \pm 49.6$ & $178.5 \pm 28$ & 0.9 \\
\hline TSH (uIU/mL) & $1.2 \pm 0.5$ & $2 \pm 0.7$ & 0.3 \\
\hline
\end{tabular}

mg: milligram; dL: deciliter; $\mu \mathrm{U}$ : micro unit; $\mathrm{mL}$ : milliliter; $\mathrm{U}$ : unit; HOMA: Homeostasis Model Assessment; IR: insulin resistance; HDL: High density lipoprotein cholesterol; LDL: Low density lipoprotein cholesterol; TSH: Thyroid-stimulating hormone, Mann-Whitney U test has been used. ${ }^{*}$ : $\mathrm{p}<0.05$ (statistically significant)

Table 1: The results of the biochemical examinations

The results of the dynamic and static balance evaluations had shown statistically significant differences when it came to dynamic balance $(\mathrm{p}<0.05)$; however there were no differences shown when it came to the results of the static balance test ( $\mathrm{p}>0.05)$, (Table 2).

\begin{tabular}{|c|c|c|c|}
\hline & Group 1 (n:18) & Group 2 (n:27) & p value \\
\hline The 15-meter “timed up and go" test $(\mathbf{s e c})$ & $9.8 \pm 1.1$ & $11.5 \pm 1.5$ & $\mathbf{0 . 0 0 4}^{*}$ \\
\hline One-leg standing test (error/30 sec) & $1.3 \pm 1.5$ & $1.4 \pm 2.3$ & 1,0 \\
\hline
\end{tabular}

Meter: Meter; sec: second; Mann-Whitney U test has been used. ${ }^{*}$ : $\mathrm{p}<0.05$ (statistically significant)

Table 2: Dynamic and static balance measurement values

Anaerobic measurement parameters were evaluated according to body weight. The peak power and average power of the group 1 were statistically significantly better than those of the second group $(\mathrm{p}<0.05)$. Even though the minimum power and power drops were better for group 1 , no statistically significant differences were shown between either group ( $\mathrm{p}>0.05)$, (Table 3).

\begin{tabular}{|c|c|c|c|}
\hline & Group 1 (n:18) & Group 2 (n:27) & p value \\
\hline PP & $3.8 \pm 1.3$ & $2.5 \pm 1.4$ & $\mathbf{0 . 0 3}^{*}$ \\
\hline AP & $3.2 \pm 1$ & $2.2 \pm 1.3$ & $\mathbf{0 . 0 4}^{*}$ \\
\hline MP & $2.3 \pm 1.3$ & $1.7 \pm 1.2$ & 0.2 \\
\hline PD & $1.5 \pm 1.1$ & $0.8 \pm 0.5$ & 0.06 \\
\hline
\end{tabular}

W: watt; kg: kilogram; PP: Peak Power; AP: Average Power; MP: Minimum Power; PD: Power

Drop; Mann-Whitney U test has been used. ${ }^{*}: \mathrm{p}<0.05$ (statistically significant)

Table 3: Anaerobic measurement parameters $(\mathrm{W} / \mathrm{kg})$

The isokinetic and isometric muscle strength parameters-which were evaluated according to body weight--were statistically significantly better for the results of group 1 the results of group $2(\mathrm{p}<0.05)$, (Table 4$)$.

\begin{tabular}{|c|c|c|c|}
\hline & Group 1 (n:18) & Group 2 (n:27) & $p$ value \\
\hline Isometric ext PT/BW & $165.9 \pm 50.1$ & $121.3 \pm 38.7$ & $0.03^{*}$ \\
\hline Isometric flex PT/BW & $95.5 \pm 25.6$ & $58.8 \pm 21.9$ & $0.003^{*}$ \\
\hline Ext PT/ BW(@60 \%/sec) & $149.9 \pm 51.2$ & $97.9 \pm 27.5$ & $0.01^{*}$ \\
\hline Flex PT/ BW(@60\%/sec) & $80.7 \pm 22.8$ & $58.6 \pm 22.1$ & 0.06 \\
\hline Ext PT/ BW(@240%/sec) & $75.2 \pm 20.5$ & $49.4 \pm 15.2$ & $0.003^{*}$ \\
\hline Flex PT/ BW(@240 \%/sec) & $52.7 \pm 14.8$ & $29 \pm 9.5$ & $0.001^{*}$ \\
\hline Ext TW/ BW(@240%sec) & $1387.9 \pm 362.8$ & $912.5 \pm 271.9$ & $0.002^{*}$ \\
\hline Flex TW/ BW(@240%/sec) & $649.2 \pm 197.7$ & $460.6 \pm 167.4$ & $0.03^{*}$ \\
\hline
\end{tabular}

PT: Peak Torque; BW: body weight; TW: Total work; sec: second; Ext: extension; Flex: Flexion; Mann-Whitney U test has been used. ${ }^{*}$ : $\mathrm{p}<0.05$ (statistically significant)

Table 4: Isometric and isokinetic muscle strength measurement parameters (Newton meter) 


\section{Discussion}

It was identified in our study that while the patients with higher body mass index had higher fasting blood glucose and triglyceride levels, they also had had lower dynamic balances, anaerobic peak power and average power values, and isometric as well as isokinetic knee muscle strengths.

Dyslipidemia is an important public health problem. The mortality rate related to cardiovascular diseases such as coronary artery disease, other artery diseases, diabetes mellitus, is increasing with each passing day around the world. Factors such as dyslipidemia, smoking, diabetes mellitus, being male, a lack of exercise, obesity, and stress all pose a risk for cardiovascular diseases. It is important to identify primary and secondary lipid and lipoprotein disorders in a person diagnosed with dyslipidemia. An increase in the number of the risk factors that an individual has increases their risk of having a cardiovascular disease. The fact is that obesity is considered now considered to be pandemic problem, and moreover the dyslipidemia affects the clinical course and functional condition of the patients more severely [26].

In general, a high TG, low HDL cholesterol level, and an increase in a more proatherogenic form of cholesterol are observed in obesity-related dyslipidemia cases. Uncontrolled fatty acid release from adipose tissue as well as an increased free fat acid in circulation leads to mRNA expression in the muscles and/or lowers the lipoprotein lipase activity, thus resulting in obesity related dyslipidemia [27].

The change in lipid forms is similar to the one in patients diagnosed with type 2 diabetes mellitus and/or insulin resistance. Population-based studies indicate that every $89 \mathrm{mg} / \mathrm{dL}$ increase in the TG level increases the risk of cardiovascular disease by $32-76 \%$ [28]. The development of microvascular organ damages due to type 2 diabetes mellitus by affecting adipocytes is also one complication of hypertriglyceridemia. Moreover, the fact that the TG/HDL cholesterol rate is higher than 3.66 increases the mortality risk as a result of myocardial ischemia in females [29]. Considering the fact that factors such as dyslipidemia, an increase in fasting glucose, insulin resistance, and obesity form the basis of metabolic syndrome, the presence of increased fasting glucose in obese individuals in our study is not surprising [28].

Muscle mass is higher in obese patients; however their level of physical activity of is usually lower [30]. Obesity related changes such as inflammation, metabolism, and reduced insulin signaling lowers muscular quality and functional capacity [30]. The function of the lower extremity is significant in daily life. For example, recurrent lower extremity muscle contractions occur while climbing up stairs or walking. Major deficiencies in these muscle groups affect lower extremity muscle strength, endurance, balance function, anaerobic capacity and, thus, overall quality of life. Obesity may result in functional limitations causing deficiencies in muscle strength and power. This condition has been examined in the literature to a limited extent [9]. There is no perfect test to evaluate the general quality of life and function. However, there is a positive correlation between tests such as the 'timed up and go' test, one-leg standing test, walking speed, standing up from the chair-all of which measure the balance and functional sufficiency level-and one's quality of life and function [31].

Hergenroeder et al. had stated that performance-based mobility (timed up and go test) decreased in individuals with a BMI greater than 35; however, performance-based balance (timed balance test) was not affected by the BMI [3]. Dutil et al. had argued that obesity clearly affects postural control in elderly women, and had supported their hypothesis with the results they provided [32]. Greve et al. had identified that there was a correlation between the BMI and postural balance by using the Biodex balance system [12]. Hue et al. had stated that body weight affected balance control, and that the most important risk of falling frequently observed in the older age groups is the loss of balance due to obesity [33]. Deforche et al. had once again proved that the lack of balance due to obesity not only occurs in elderly people but also in adolescents, and that weight affects their postural balance [34]. Kemmler et al. had stated that there was a decrease in the time of the 'timed up and go test' together with weight loss and exercise, and that there was an increase in the isometric body extensor strength, leg press strength, and power, and fitness level, indicating that the balance function could be improved together with the weight-loss [11].

Although anaerobic energy systems are rarely used in daily life, all energy systems are interconnected with one other. It can be predicted that every ounce of extra weight will affect anaerobic capacity. Kitagawa et al. had identified that anaerobic power in obese individuals as well as anaerobic power in proportion to fat-free body weight were higher in obese individuals [35]. Lafortuna et al. had determined that when they evaluated short-term alactic anaerobic performance with jump, sprint and stair climb tests, the power output of obese individuals per each kilogram was lower [10]. One study by Żak-Gołąb et al. had examined the effect of including obese individuals in the weight control program and losing weight--after they had evaluated the anaerobic thresholds of both obese and non-obese individuals [4]. In their final report, they presented that the lactate and ventilatory thresholds were higher, and that there was no change in accompaniment with weight loss.

Different factors and opposite results affecting the muscle performance at the cellular level in obese individuals were reported. One of which is that the skeletal muscle in obese individuals will have a high interstitial adipocyte level, and that it will reduce muscle quality in different pathophysiological ways. According to another opinion, it was supported that the amount of type 1 slow-twitch muscle fibers is related to the amount of fat, and that perhaps this situation can explain the fact that obese individuals are advantageous during anaerobic work [10]. 
Another parameter that can be evaluated in relation to the BMI is muscle strength and endurance. Podstawski et al. had reported that endurance and strength were lower in overweight and obese individuals, and that every $1 \%$ of increase in the BMI would cause a $0.93 \%$ decrease in the Burpee test [7]. Deforche et al. had stated that while obese youth receive lower results in 'standing-broad jump, sit-ups, bent-armhang, speed shuttle run and endurance shuttle run' tests, their hand grip strength was higher [34]. When Lazarus et al. had measured hand grip strength under the opinion that there might be a negative relationship between insulin resistance, and physical activity, and muscle strength, they found out that hand grip muscle strength was lower in individuals with high insulin resistance [36]. Carvalho et al. had indicated that the cardiorespiratory fitness level, concentric, and isometric knee extensor muscle strength and endurance were lower in young obese women when versus normal-weight individuals [22]. Jurca et al. had reported that the lower and upper extremity muscle strength of individuals with metabolic syndrome was lower [37].

Exercise prescriptions for dyslipidemic patients are principally similar to normal population. However, in order to activate fat degradation at skeletal system, moderate to vigorous intensity physical activity and that it should be long-lasting. Exercise prescription for obese patients should result in negative energy balance and stimulates lipolysis [38]. For such patients, the American College of Sports Medicine recommends anywhere from 30-60 minutes of moderate to vigorous exercises per day to a total of 150-250 minutes of exercise per week, or an approximately 1200-2000 kcal/week energy expenditure. Saris et al. recommends 225-300 minute/week worth of exercise. Resistance exercises have a very low effect on lowering body weight alone. However resistance exercises have shown to be effective when it comes to muscle strength, as well as to resolve the age related sarcopenia. Resistance exercises combined with aerobic exercises helps to control glucose levels as well as more significantly lower the hemoglobin Alc levels [39]. Balance exercises reduce the number of situations of imbalance, of the risk of falling,, and of postural swinging - all of which were tied to obesity $[39,40]$. As a result of these positive effects, strength and balance exercises should not be neglected for dyslipidemic patients who are obese.

\section{Conclusion}

According to the data obtained in our study, the presence of the body mass index increases the negative impact on the metabolic and functional capacity of individuals with with dyslipidemia. The fight against obesity will provide great benefits to people and to society when it comes to the treatment of chronic diseases.

\section{References}

1.Bayram F, Kocer D, Gundogan K, Kaya A, Demir O, et al. (2014) Prevalence of dyslipidemia and associated risk factors in Turkish adults. J Clin Lipidol 8: 206-16.

2. Kêkê LM, Samouda H, Jacobs J, Hubert H, Zitouni D et al. (2015) Body mass index and childhood obesity classification systems: A comparison of the French, International Obesity Task Force (IOTF) and World Health Organization (WHO) references. Rev Epidemiol Sante Publique 63: 173-82.

3. Hergenroeder AL, Wert DM, Hile ES, Studenski SA, Brach JS (2011) Association of body mass index with self-report and performance-based measures of balance and mobility. Phys Ther 91: 1223-34.

4. Zak-Golab A, Zahorska-Markiewicz B, Langfort J, Kocelak P, Holecki M, et al. (2010) The influence of weight loss on anaerobic threshold in obese women. J Sports Sci Med 9: 564-71.

5. Bulur Ş, Çeçen S, Eren F (2014) Anthropometric and biochemical characteristics of the individuals applying to the department of sports physiology with the complaint of overweight [Spor fizyolojisi bölümüne fazla ilo yakınması ile başvuran bireylerin antropometrik ve biyokimyasal özellikleri]. ADÜ Tıp Fak Derg 15: 29-35.

6. Addison O, Marcus RL, Lastayo PC, Ryan AS (2014) Intermuscular fat: a review of the consequences and causes. Int J Endocrinol 10.1155/2014/309570.

7. Podstawski R, Bernard K, Tomasz B, Michał B, Dariusz C (2013) Relationship between BMI and endurance-strength abilities assessed by the 3 minute burpee test. J Sports Sci 3: 28-35.

8. Aydogan U, Eroglu A, Akbulut H, Yildiz Y, Gok DE, et al. (2012) Evaluation of the isokinetic muscle strength, balance and anaerobic performance in patients with young male hypogonadism. Endocrine 59: 321-7.

9. Maffiuletti NA, Ratel S, Sartorio A, Martin V (2013) The impact of obesity on in vivo human skeletal muscle function. Curr Obes Rep 2: 251-60.

10. Lafortuna CL, Fumagalli E, Vangeli V, Sartorio A (2002) Lower limb alactic anaerobic power output assessed with different techniques in morbid obesity. J Endocrinol Invest 25: 134-41.

11. Kemmler W, vonStengel S, Engelke K, Häberle L, Mayhew JL, et al. (2010) Exercise, body composition, and functional ability: a randomized controlled trial. Am J Prev Med 38: 279-87.

12. Greve J, Alonso A, Bordini AC, Camanho GL (2007) Correlation between body mass index and postural balance. Clinics 62: 717-20.

13. Pattyn N, Cornelissen VA, Eshghi SRT, Vanhees L (2013) The effect of exercise on the cardiovascular risk factors constituting the metabolic syndrome. Sports Med 43: 121-33.

14. Şen H, Dönderici Ö, Cengiz O (2007) The frequency of subclinical hypothyroidism in patients with dyslipidemia. Turkiye Klinikleri J Med Sci 27: 344-9.

15. Messier V, Malita FM, Rabasa-Lhoret R, Brochu M, Karelis AD (2008) Association of cardiorespiratory fitness with insulin sensitivity in overweight and obese postmenopausal women: a Montreal Ottawa New Emerging Team study. Metabolism 57: 1293-8.

16. Kara İH (2012) The examination of haematological and biochemical parameters in obese women at the age of reproduction. Konuralp Tip Derg 1-7.

17. Xu X, Mirka GA, Hsiang SM (2008) The effects of obesity on lifting performance. Appl Ergon 39: 93-8.

18. Balaban Ö, Nacir B, Erdem HR (2009) The evaluation of balance function. J Phys Med Rehabil Sci 12: 133-9.

19. Schoppen T, Boonstra A, Groothoff JW, de Vries J, Göeken LN, et al. (1999) The Timed "up and go" test: reliability and validity in persons with unilateral lower limb amputation. Arch Phys Med Rehabil 80: 825-8.

20. Hrysomallis C (2007) Relationship between balance ability, training and sports injury risk. Sports Med 37: 547-56. 
21. Laurent CM, Meyers MC, Robinson CA, Green JM (2007) Cross-validation of the 20-versus 30-s wingate anaerobic test. Eur J Appl Physiol 100: 645-51. 22. Carvalho LP, DiThommazo-Luporini L, Aubertin-Leheudre M, Luporini RL, Mendes RG, et al. (2015) Prediction of cardiorespiratory fitness by the six-minute step test and its association with muscle strength and power in sedentary obese and lean young women: a cross-sectional study. PLoS one 10: e0145960.

23. Karagiannidis E, Patsika G, Kellis E, Galanis N, Vasilioset B (2016) Hamstring muscle activation during maximum isometric tests in individuals with anterior cruciate ligament reconstruction and controls. IJIR 2: 2011-7.

24. Ghroubi S, Kossemtini W, Mahersi S, Elleuch W, Chaabene M, et al. (2016) Contribution of isokinetic muscle strengthening in the rehabilitation of obese subjects. Ann Phys Rehabil Med 59: 87-93.

25. Dalton BH, Power GA, Paturel JR, Rice CL (2015) Older men are more fatigable than young when matched for maximal power and knee extension angular velocity is unconstrained. Age 37: 10.1007/s11357-015-9790-0.

26. Tamer İ, Dabak R, Tamer G (2008) Hyperlipidemia in the light of current guides. RNA Aile Hekimliği Dergisi 2: 6-10.

27. Jung UJ, Choi MS (2014) Obesity and its metabolic complications: the role of adipokines and the relationship between obesity, inflammation, insulin resistance, dyslipidemia and nonalcoholic fatty liver disease. Int J Mol Sci 15: 6184-223.

28. Franssen R, Monajemi H, Stroes ES, Kastelein JJ (2011) Obesity and dyslipidemia. Med Clin North Am 95: 893-902.

29. Bays HE, Toth PP, Kris-Etherton PM, Abate N, Aronne LJ, et al. (2013) Obesity, adiposity, and dyslipidemia: a consensus statement from the National Lipid Association. J Clin Lipidol 7: 304-83.

30. Erskine RM, Tomlinson DJ, Morse CI, Winwood K, Hampson P, et al. (2017) The individual and combined effects of obesity-and ageing-induced systemic inflammation on human skeletal muscle properties. Int J Obes 41:102-11.

31. Han TS, Wu FCW, Lean ME (2013) Obesity and weight management in the elderly: a focus on men. Best Pract Res Clin Endocrinol Metab $27: 509-25$.

32. Dutil M, Handrigan GA, Corbeil P, Cantin V, Simoneau M, et al. The impact of obesity on balance control in community-dwelling older women. Age 35: 88390.

33. Hue O, Simoneau M, Marcotte J, Berrigan F, Doré J, et al. (2007) Body weight is a strong predictor of postural stability. Gait Posture 26: $32-8$.

34. Deforche B, Lefevre J, Bourdeaudhuij I, Hills AP, Duquet W, et al. (2003) Physical fitness and physical activity in obese and nonobese Flemish youth. Obes Res 11(3): 434-41.

35. Kitagawa K, Suzuki M, Miyashita M (1980) Anaerobic power output of young obese men: Comparison with non-obese men and the role of excess fat. Eur J Appl Physiol 43: 229-34.

36. Lazarus R, Sparrow D, Weiss ST (1997) Hand grip strength and insulin levels: Cross-sectional and prospective associations in the Normative Aging Study. Metabolism 46: 1266-9.

37. Jurca RADIM, Lamonte MJ, Church TS, Earnest CP, Fitzgerald SJ, et al. (2004) Associations of muscle strength and aerobic fitness with metabolic syndrome in men. Med Sci Sports Exerc 36: 1301-7.

38. Pedersen BK, Saltin B (2015) Exercise as medicine-evidence for prescribing exercise as therapy in 26 different chronic diseases. Scand J Med Sci Sports 25:1-72. 39. Saris WHM, Blair SN, Van Baak MA, Eaton SB, Davies PS, et al. (2003) How much physical activity is enough to prevent unhealthy weight gain? Outcome of the IASO 1st Stock Conference and consensus statement. Obes Rev 4: 101-14.

40. Jonas S, Phillips EM (2009) ACSM’s Exercise is Medicine ${ }^{\mathrm{tx}}$ : A Clinician's Guide to Exercise Prescription (1 ${ }^{\text {st }}$ Edn) Philadelphia: Lippincott Williams \& Wilkins, USA. 